\title{
Tyrosine phosphorylation of botulinum neurotoxin protease domains
}

\section{Stephen Toth ${ }^{1 \dagger}$, Ernst E. Brueggmann ${ }^{1}$, George A. Oyler ${ }^{2}$, Leonard A. Smith ${ }^{3}$, Harry B. Hines ${ }^{1}$ and S. Ashraf Ahmed ${ }^{1}$ *}

\author{
Integrated Toxicology Division, Department of Biochemistry and Cell Biology, United States Army Medical Research Institute of Infectious Diseases, Fort Detrick, \\ MD, USA \\ 2 Synaptic Research LLC, Baltimore, MD, USA \\ ${ }^{3}$ Office of the Chief Scientist, Fort Detrick, MD, USA
}

\section{Edited by:}

Chiranjib Chakraborty, School of Bio-Sciences and Technology - VIT University, India

Reviewed by:

Joel Tyndall, University of Otago, New Zealand

Miaozong Wu, Marshall University, USA

*Correspondence:

S. Ashraf Ahmed, USAMRIID, 1425

Porter Street, Fort Detrick, MD 21702,

USA.

e-mail: syed.ahmed@amedd.army.mil

${ }^{t}$ Present address:

Stephen Toth, Mentor Biologics,

Madison, WI 53711, USA
Botulinum neurotoxins are most potent of all toxins. Their N-terminal light chain domain (LC) translocates into peripheral cholinergic neurons to exert its endoproteolytic action leading to muscle paralysis. Therapeutic development against these toxins is a major challenge due to their in vitro and in vivo structural differences. Although three-dimensional structures and reaction mechanisms are very similar, the seven serotypes designated $A$ through $G$ vastly vary in their intracellular catalytic stability. To investigate if protein phosphorylation could account for this difference, we employed Src-catalyzed tyrosine phosphorylation of the LC of six serotypes namely $L c A, L c B, L c C 1, L c D, L c E$, and $L c G$. Very little phosphorylation was observed with $L c D$ and $L c E$ but $L c A, L c B$, and $L c G$ were maximally phosphorylated by Src. Phosphorylation of $L c A, L c B$, and $L c G$ did not affect their secondary and tertiary structures and thermostability significantly. Phosphorylation of Y250 and Y251 made LcA resistant to autocatalysis and drastically reduced its $k_{\text {cat }} / K_{m}$ for catalysis. A tyrosine residue present near the essential cysteine at the $\mathrm{C}$-terminal tail of $\mathrm{LCA}, \mathrm{LcB}$, and $\mathrm{LcG}$ was readily phosphorylated in vitro. Inclusion of a competitive inhibitor protected Y426 of LcA from phosphorylation, shedding light on the role of the C-terminus in the enzyme's substrate or product binding.

Keywords: botulinum neurotoxin, tyrosine phosphorylation, zinc endoporotease, protease, clostridium botulinum, protein phosphorylation

\section{INTRODUCTION}

Botulinum neurotoxins $(\mathrm{BoNTs})^{1}$ are among the most lethal of all toxins and are also potential biowarfare agents (Cochrane, 1947; Gill, 1982; Montecucco and Schiavo, 1995; Arnon et al., 2001). Enormous efforts are devoted toward therapeutic development against these targets (see examples in the references (Schmidt and Stafford, 2005; Hines et al., 2008; Zuniga et al., 2008; Agarwal et al., 2009; Burnett et al., 2009; Capkova et al., 2009; Ludivico et al., 2009; Pang et al., 2009; Silhar et al., 2010; Hale et al., 2011). A thorough understanding of their structure under cellular environment is therefore essential.

\footnotetext{
Abbreviations: BoNT, botulinum neurotoxin; BoNT/A-G, BoNT serotypes A, B, C, D, E, F, G; BSA, bovine serum albumin; CD: circular dichroism; CFP, cyan fluorescent protein; DSC: differential scanning calorimetry; DTT, dithiothreitol; DPBS, Dulbecco's phosphate-buffered saline; HEPES, (4-(2-hydroxyethyl)1-piperazineethanesulfonic acid); EGTA, ethylene glycol tetra acetic acid; FTIR: Fourier transform infra red; HRP, horseradish peroxidase; LC, light chain LcA, light chain of serotype A; LcA-phos, phosphorylated LcA; LcB-Phos, phosphorylated LcB; LcB, light chain of serotype B; LcC1, light chain of serotype C1; LcD, light chain of serotype D; LcE, light chain of serotype E; LcG, light chain of serotype G; LcG-Phos, phosphorylated LcG; SBP: streptavidin binding protein; SNAP-25, synaptosome-associated protein of $25 \mathrm{kDa}$; TFA, trifluoroacetic acid; Tm: melting temperature; TMB, 3,3' $5,5^{\prime}$-tetramethylbenzidine; UPLC, ultra performance liquid chromatography; VAMP, vesicle-associated membrane protein.
}

These $150 \mathrm{kDa}$ exotoxins are produced by strains of Clostridium botulinum as seven distinct serotypes, designated BoNT/A-G. After finding their way through oral, respiratory, or wound routes to the animal body, BoNTs travel to peripheral cholinergic neuronal cells and are internalized by endocytosis followed by translocational delivery of its $50 \mathrm{kDa}$ light chain $(\mathrm{Lc})$ from endosome into the cytosol (Simpson, 2004). The free Lc, a zinc-endopeptidase (Schiavo et al., 1992a), exerts its proteolytic activity at specific sites on one of the three synaptosomal proteins, SNAP-25, VAMP, or syntaxin. For example, the Lc of BoNT/A (LcA) and BoNT/E (LcE) cleave at specific but different sites on SNAP-25 (Schiavo et al., 1993), while Lc of BoNT/B (LcB) and BoNT/D (LcD) cleaves at distinct but different sites on VAMP (Schiavo et al., 1992b). The process prevents fusion of synaptosomes with the cell membrane, blocking acetylcholine release into the neuromuscular junction. The resultant effect is muscle paralysis and eventual death if the intoxication is severe and not treated.

The overall polypeptide fold and three-dimensional structures of all BoNT serotypes are almost identical (Lacy et al., 1998; Eswaramoorthy et al., 2002; Agarwal et al., 2004, 2005; Arndt et al., 2005, 2006; Jin et al., 2007; Kumaran et al., 2008a), and they appear to follow the same reaction mechanism using the conserved active site residues (Agarwal et al., 2004; Swaminathan et al., 2004; Kumaran et al., 2008a). In spite of their in vitro 
structural and mechanistic identity, duration of BoNT serotypedependent paralysis in animal cells varies widely. For example, in humans BoNT/A-induced paralysis can persist for more than a year (Souayah et al., 2006). BoNT protease activity and toxicity in rat cerebellar and mouse spinal cord neurons lasts from 3 months for BoNT/A to less than a day for BoNT/E (Keller et al., 1999; Foran et al., 2003). Thus, the structure of the Lc domain inside neurons can be expected to vary widely to account for these differences. One possible source of structural variations may be through post-translocational modifications that include phosphorylation, palmitoylation, and ubiquitination, among others (Walsh, 2006a).

Post-translational modification of proteins in eukaryotic cells can generate 10 to 100 -fold more variants than the 30,000 protein products of the human genome, imparting the same protein with various regulatory, secretory, catalytic, and structural functions (Walsh, 2006a). For example, SNAP-25 (Nagy et al., 2004), VAMP (Nielander et al., 1995), and syntaxin (Foster et al., 1998) among hundreds of synaptosomal proteins in neuronal cells undergo phosphorylation at specific sites (Munton et al., 2007 ) in performing and regulating various functions. Because the prokaryotic BoNT Lc exerts its catalytic action on synaptosomal proteins and survives within the eukaryotic neurons for extended times (Keller et al., 1999; Souayah et al., 2006), it might be subjected to phosphorylation. Indeed, in an attractive demonstration, Ferrer-Montiel et al. (1996) reported that BoNT/A Lc undergoes tyrosine phosphorylation inside PC12 cells and in vitro (Encinar et al., 1998; Blanes-Mira et al., 2001; Ibanez et al., 2004). The non-receptor tyrosine kinase, Src and PYK2 that are abundant in these cells was efficient and specific in this phosphorylation reaction. Src-catalyzed phosphorylation of LcA displayed elevated proteolytic activity and thermal stability. Because both Src and PYK2 are highly abundant in brain and neuroendocrine cells, it was postulated that tyrosine phosphorylation may modulate Lc activity within neurons (Ferrer-Montiel et al., 1996). This ex vivo demonstration of Lc phosphorylation has not been verified independently.

In this paper, we report our in vitro investigation of tyrosine phosphorylation of eight versions of Lc from the six serotypes of BoNT/A, BoNT/B, BoNT/C1, BoNT/D, BoNT/E, and BoNT/G. Our results showed while $\mathrm{LcA}, \mathrm{LcB}, \mathrm{LcC} 1$, and $\mathrm{LcG}$ were readily phosphorylated, LcD and LcE were poorly phosphorylated. One tyrosine residue near the interchain disulfide-forming cysteine at the C-terminus was phosphorylated in LcA, LcB, and LcG. In addition, two C-terminally truncated LcA forms, LcA420, and LcA424, were also phosphorylated. Phosphorylation of LcA was accompanied by loss of catalytic activity, without changes in secondary and tertiary structures and thermal denaturation but made it highly resistant to autocatalytic degradation due to phosphorylation of two tyrosine residues at the autocatalytic site. Phosphorylation of LcB marginally increased thermal stability and catalytic activity.

\section{EXPERIMENTAL PROCEDURES MATERIALS}

Recombinant BoNT protease light chains of serotype A (LcA) and serotype $\mathrm{B}(\mathrm{LcB})$ were purified as described (Ahmed et al., 2003; Jensen et al., 2003; Gilsdorf et al., 2006), and similar purification of serotypes $D(\mathrm{LcD})$, and $\mathrm{G}$ will be published elsewhere; LcE was purchased from BBtech (MA). Truncated versions of LcA containing the first 420 (LcA420; Segelke et al., 2004) and 424 residues (LcA424; Kumaran et al., 2008a), and of LcC1 containing the first 430 residues (Rawat et al., 2008) were purified as described. Although the full-length LcA used here contains an extra valine after the initial methionine at the $\mathrm{N}$ terminus, residue numbering used in this manuscript are according to GenBank ID LcA1: AAQ06331; LcB1:BAE48264; LcC1: CAA44263; LcD1: AAB24244; LcE1: BAB86845; LcF1:ADA79551; LcG: CAA52275. Before the phosphorylation reaction, each light chain $(0.5-1 \mathrm{mg} / \mathrm{ml})$, with the exception of LcA, was brought to room temperature and then incubated with $0.25 \mathrm{mM} \mathrm{ZnCl}_{2}$ on ice for $30 \mathrm{~min}$, followed by gel-filtration on a PD-10 column in $10 \mathrm{mM}$ Na-phosphate, $\mathrm{pH}$ 7.4. LcA was directly applied to a PD-10 column without pre-treatment with $\mathrm{ZnCl}_{2}$. Src (1255 units/mg, $0.1 \mathrm{mg} / \mathrm{ml}$ ), monoclonal anti-Src (GD11 and 4G10) antibody kits, and Western blot reagents were from Millipore, Billerica, MA, USA (previously Upstate Biotechnology Inc. Temecula, CA, USA). Sequence-derived substrates from SNAP-25 for LcA (SNKTRIDEANQ-RATKML), and from VAMP for LcB (LSELDDRADALQAGASQ-FETSAAKLKRKYWWKNLK; Foran et al., 1994), and another VAMP sequence-derived substrate peptide for LcD (LQQTQAQVDEVVDIMRVNVDKVLERDQKLSELDD; Rowe et al., 2010), all having N-terminal acetylated and C-terminal amidated, were custom-synthesized and purified to $>95 \%$ by Quality Controlled Biochemicals (Hampton, MS, USA).

\section{PHOSPHORYLATION REACTION}

Phosphorylation reaction was performed according to the manufacturer's protocol. Briefly, LcA $(0.55 \mathrm{mg} / \mathrm{ml})$, LcA424 $(0.28 \mathrm{mg} / \mathrm{ml}), \quad$ LcA420 $(0.18 \mathrm{mg} / \mathrm{ml}), \quad$ LcB $(0.17 \mathrm{mg} / \mathrm{ml}, \quad$ LcC $(0.49 \mathrm{mg} / \mathrm{ml}), \operatorname{LcD}(0.29 \mathrm{mg} / \mathrm{ml}), \mathrm{LcE}(0.02 \mathrm{mg} / \mathrm{ml})$, or $\mathrm{LcG}$ $(0.27 \mathrm{mg} / \mathrm{ml})$ was incubated on ice with $20 \mathrm{mM}$ HEPES $\mathrm{pH}$ 7.4, 2 mM DTT (final concentrations) followed by addition of $1 \mathrm{mM}$ EGTA, $20 \mathrm{mM} \mathrm{MgCl}_{2}, 2 \mathrm{mM}$ ATP, and three units of Src $(0.025 \mathrm{mg} / \mathrm{ml})$ in a total reaction volume of $0.1 \mathrm{ml}$. Concentration of the reagents, and the ratio of $\mathrm{Lc}(\mathrm{mg})$ to $\mathrm{Src}$ (units) were same as in the literature except that $2 \mathrm{mM}$ used here was higher than $0.5 \mathrm{mM}$ (Ferrer-Montiel et al., 1998; Blanes-Mira et al., 2001; Ibanez et al., 2004). The final reaction mixtures were incubated at $30^{\circ} \mathrm{C}\left(20^{\circ} \mathrm{C}\right.$ for $\left.\mathrm{LcA}\right)$ for $24 \mathrm{~h}$. For mass spectrometric analysis, $6 \mu \mathrm{l}$ of the reaction mixture was removed at various times and $6 \mu l$ of $0.5 \%$ trifluoroacetic acid was added to each aliquot. For SDS-PAGE and Western blot analyses, $12 \mu \mathrm{l}$ of $2 \times$ SDS-load buffer was added to $6 \mu \mathrm{l}$ aliquot of the stopped reaction mixture. Duplicate SDS-PAGE gels were run simultaneously, one for protein visualization by Coomassie stain, the other for Western blot using horseradish peroxide-anti-phosphotyrosine antibody. For catalytic activity measurements, the reaction mixture was diluted with ice-cold $50 \mathrm{mM}$ HEPES $\mathrm{pH} 7.4$ for immediate activity determination by UPLC. Alternately, in large-scale preparations, phosphorylation reaction was stopped by removing the Src with sepharose beads containing monoclonal anti-Src antibody. Unless otherwise stated, Western blot bands were visualized using electrochemical luminescent stain. 
Preparative phosphorylation utilized LcA $(0.58 \mathrm{mg} / \mathrm{ml}), \mathrm{LcB}$ $(0.9 \mathrm{mg} / \mathrm{ml})$, or LcG $(1.5 \mathrm{mg} / \mathrm{ml})$ in volumes of $1.5-3.0 \mathrm{ml}$ containing all other components. Aliquots were tested for completion of phosphorylation at intervals from $15 \mathrm{~min}$ to $48 \mathrm{~h}$ for Western blot and mass spectrometric analyses. If the phosphorylation reaction was incomplete, incubation was continued for up to 5 days with additional Src and ATP. The reactions were stopped by addition of monoclonal anti-Src-agarose followed by storage at $4^{\circ} \mathrm{C}$ for $24 \mathrm{~h}$. Phosphorylated product in the soluble fraction was passed through a PD-10 column and collected in $50 \mathrm{mM}$ Na-phosphate buffer, $\mathrm{pH}$ 6.8. The dilute protein fractions were combined, concentrated on Centricon-10 microconcentrators, washed, and collected in the same buffer for further analyses.

The standard tyrosine phosphorylation reaction component of the Src supplier included $20 \mathrm{mM} \mathrm{MgCl}_{2}$ and $20 \mathrm{mM}$ Tris- $\mathrm{HCl}, \mathrm{pH}$ 7.4. We replaced Tris with HEPES in the assays because it gave optimum Lc catalytic activity while the manufacturer suggested Tris- $\mathrm{HCl}$ is inhibitory to Lc enzyme activity (Ahmed and Smith, 2000). After 3-24 h incubation with tyrosine kinase Src, Coomassie staining of the proteins after SDS-PAGE showed (Figure 1) all BoNT serotypes remained stable in retaining their linear structures in the $\mathrm{Src}$ reaction mixture $(0.1 \mathrm{ml})$. In large-scale phosphorylation reactions using $\mathrm{LcB}$ and $\mathrm{LcG}(\sim 3 \mathrm{mg}, 2 \mathrm{ml})$, the proteins remained soluble after $48 \mathrm{~h}$ of incubation at $30^{\circ} \mathrm{C}$. Large-scale $(2 \mathrm{mg}, 2 \mathrm{ml})$ reactions with LcA using standard conditions resulted in precipitation of most of the protein within $24 \mathrm{~h}$. Close observation revealed the appearance of fine LcA precipitate soon after start of the incubation, similar to the one observed by gentle stirring at a lower temperature and at various protein concentrations (Toth et al., 2009). Most of the remaining soluble protein showed autocatalyzed fragmentation products, most likely due to presence of the divalent $\mathrm{Mg}^{++}$ion (Ahmed et al., 2004) and a prolonged incubation temperature of $30^{\circ} \mathrm{C}$ (Ahmed et al., 2001, 2003, 2004). We therefore excluded $\mathrm{ZnCl}_{2}$ pre-treatment of $\mathrm{LcA}$ and varied the temperature of Src reaction incubation. We found that incubation at $20^{\circ} \mathrm{C}$ for up to $120 \mathrm{~h}$ prevented LcA precipitation and autocatalytic fragmentation. Therefore, a preparative amount of LcA-phos was prepared by incubating $3 \mathrm{ml}(1.6 \mathrm{mg}) \mathrm{LcA}$ with $0.02 \mathrm{mg} \mathrm{Src} \mathrm{at}$ $20^{\circ} \mathrm{C}$ for $48 \mathrm{~h}$. Because the enzymatic tyrosine phosphorylation activity of Src varied from batch to batch, its concentration in the reaction mixture was adjusted between experiments to yield saturating phosphorylation as monitored by ESI-MS at various time points (see later).

Molecular mass of Lc target proteins, $\sim 51 \mathrm{kDa}$, was close to that of the Src of $\sim 60 \mathrm{kDa}$, and Src underwent self-phosphorylation. These two factors may lead to an incorrect interpretation of the Western blot results. We therefore continued electrophoresis $(120 \mathrm{~V}, 90 \mathrm{mAmp})$ for a minimum of $1.5 \mathrm{~h}$ to clearly separate the two proteins (Figure 1A).

\section{UV-VISIBLE ABSORPTION, CIRCULAR DICHROISM, AND FLUORESCENCE MEASUREMENTS}

To determine protein concentration and to assess purity, UVvisible absorption spectra were recorded at $22^{\circ} \mathrm{C}$ with a HewlettPackard 8452 diode array spectrophotometer. Lc concentration was determined using $A^{0.1 \%}$ ( $1 \mathrm{~cm}$ path length) value of 1.0 at $278 \mathrm{~nm}$ (Ahmed et al., 2001) or by BCA assay (Pierce) with BSA as standard. Both methods gave the same result.

Circular dichroism spectra were recorded at $20^{\circ} \mathrm{C}$ with a Jasco 718 spectropolarimeter with quartz cuvettes of $2 \mathrm{~mm}$ path length. An average of five scans was recorded to increase signal-to-noise ratio at a scan speed of $20 \mathrm{~nm} / \mathrm{min}$ with a response time of $8 \mathrm{~s}$. In all measurements a buffer blank was recorded separately and subtracted from sample recordings.

Tryptophan fluorescence emission spectra were recorded at $20^{\circ} \mathrm{C}$ in a PTI QuantaMaster Spectrofluorimeter, Model RTC 2000 equipped with a Peltier controlled thermostat and Felix software package. Emission and excitation slit widths were set at $1 \mathrm{~nm}$ and excitation wavelength at $295 \mathrm{~nm}$. Each spectrum was an average of five scans.

\section{MASS SPECTROMETRY}

Tryptic peptide data were acquired using a Finnigan LCQ quadrupole ion trap mass spectrometer (Thermo Electron Corporation, San Jose, CA, USA) equipped with a New Objective nanoelectrospray source (Woburn, MA, USA) and an Agilent 1100 nanoHPLC system (San Jose, CA, USA). Eight microliters of each tryptic digest were injected onto a New Objective capillary LC column $(10 \mathrm{~cm} \times 75 \mu \mathrm{m})$ packed with Biobasic C18 $(5 \mu \mathrm{m}$ particle size, $300 \AA$ pore size). Peptides were eluted using a flow rate of $500 \mathrm{~nL} / \mathrm{min}$ with flow splitting and the following linear gradient: $0-80 \% \mathrm{~B}$ in $60 \mathrm{~min}$. Solvents A and B consisted of $0.1 \%$ formic acid and $90 \%$ acetonitrile in $0.1 \%$ formic acid, respectively. The electrospray voltage was $2.0 \mathrm{kV}$. The mass spectrometer was operated using data-dependent MS/MS acquisition.

Phosphorylation sites were identified using Bioworks 3.2 software (Thermo Electron Corporation, San Jose, CA, USA) and the NCBInr database (13Oct06). Identified peptides were further evaluated using a $C$. botulinum taxonomy filter and charge state versus cross-correlation scores (XCorr). The XCorr criteria for positive identification of tryptic peptides were values $>1.9$ for singly charged ions, values $>2.2$ for doubly charged ions, and values $>2.9$ for triply charged peptides.

\section{ENZYMATIC ACTIVITY ASSAYS}

Activity assays were based on UPLC separation and measurement of the cleaved products from a 17-residue SNAP-25 peptide for LcA, 35-residue VAMP peptide for LcB, and 34-residue VAMP peptide for LcD (Rowe et al., 2010). A master reaction mixture lacking the Lc was prepared and aliquots were stored at $-20^{\circ} \mathrm{C}$. Stocks of $0.05-0.07 \mathrm{mg} / \mathrm{ml} \mathrm{Lc}$ in $50 \mathrm{mM} \mathrm{Na-HEPES,} \mathrm{pH} 7.4$ containing $0.05 \%$ Tween-20 were stored at $-20^{\circ} \mathrm{C}$. Before assay, a $\mathrm{Lc}$ stock was thawed and diluted further in $50 \mathrm{mM}$ HEPES, $\mathrm{pH} 7.4$ containing bovine serum albumin (BSA). At the time of assay, $5 \mu \mathrm{l}$ of the diluted $\mathrm{LC}$ was added to $25 \mu \mathrm{l}$ of the thawed master mix to initiate the enzymatic reaction. Components and final concentration in this $30 \mu \mathrm{l}$ reaction mixture were $0.9 \mathrm{mM}$ substrate peptide, $0.2 \mathrm{mg} / \mathrm{ml} \mathrm{BSA}, 0.0026 \mathrm{mg} / \mathrm{ml} \mathrm{LC}, 0.25 \mathrm{mM} \mathrm{ZnCl}_{2}, 5 \mathrm{mM}$ dithiothreitol, and $50 \mathrm{mM} \mathrm{Na}$-HEPES, pH 7.4. After $5-10 \mathrm{~min}$ at $37^{\circ} \mathrm{C}$, the reactions were stopped by adding $90 \mu \mathrm{l}$ of $1 \%$ trifluoroacetic acid. 

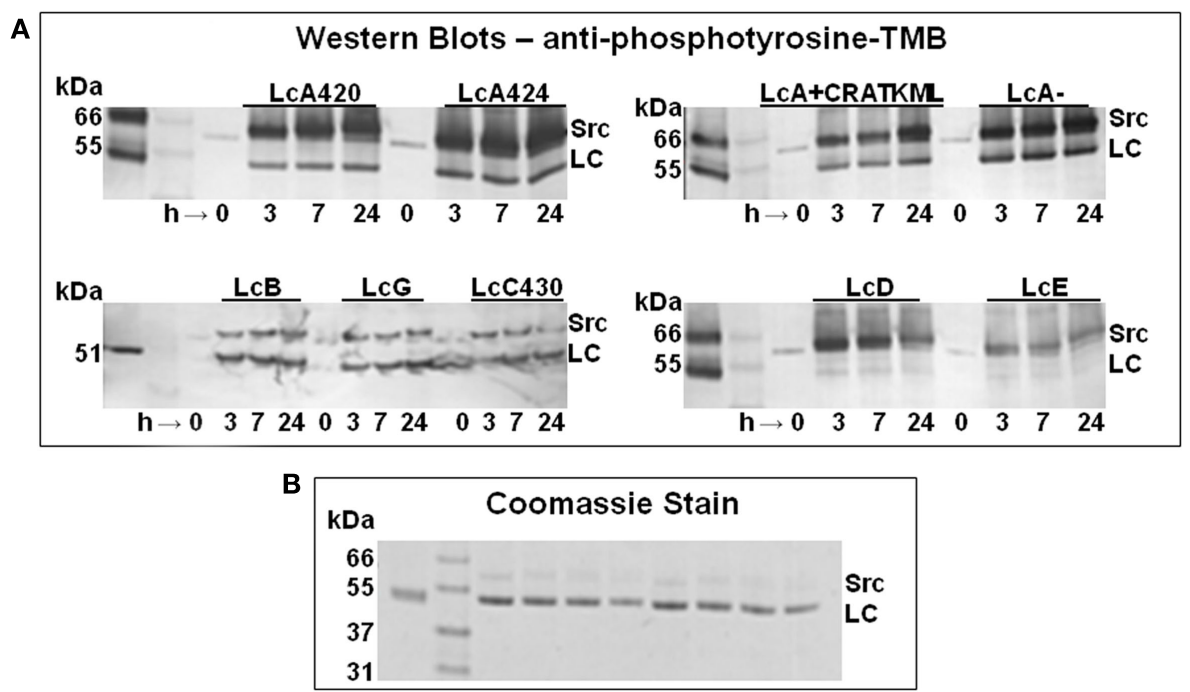

FIGURE 1 | (A) Anti-phosphotyrosine Western blot of the time course of tyrosine phosphorylation of a truncated LCA having residues 1-420 (LCA420), another truncated version of LcA having residues 1-424 (LcA424), full-length LCA alone (LCA) or in presence of $200 \mu \mathrm{M}$ of an inhibitor (LCA + CRATKML), $L c B, L c G$, a truncated version of $L c C 1$ having residues $1-430, L c D$, and $L c E$.

The amounts of uncleaved substrate and the products were measured after separation by a Waters Acquity UPLC system equipped with Empower Pro software employing a reverse-phase C18 column $(2.1 \mathrm{~mm} \times 50 \mathrm{~mm}, 1.7-\mu \mathrm{m}$ particle size $)$ with $0.1 \%$ trifluoroacetic acid as solvent $\mathrm{A}$ and $70 \%$ acetonitrile $/ 0.1 \%$ trifluoroacetic acid as solvent $\mathrm{B}$ at a flow rate of $0.5 \mathrm{ml} / \mathrm{min}$ (Rowe et al., 2010). LcA and LcC1 substrate and products were resolved by UPLC with a $0-42 \%$ gradient of the solvent B over $2 \mathrm{~min}$, followed by column regeneration for $0.7 \mathrm{~min}$. $\mathrm{LcB}$ substrate and products were resolved by UPLC with a $0-100 \%$ gradient of the solvents over $2 \mathrm{~min}$, held at $100 \% \mathrm{~B}$ for $0.5 \mathrm{~min}$, followed by column regeneration for $0.5 \mathrm{~min}$ (Rowe et al., 2010). LcD substrate and products were resolved by UPLC with a 10-25\% B over $1 \mathrm{~min}, 25-55 \% \mathrm{~B}$ for $0.5 \mathrm{~min}$, held at 55\% B for $10 \mathrm{~s}, 100 \%$ B for $1.1 \mathrm{~min}$, followed by column regeneration for $0.7 \mathrm{~min}$ (Rowe et al., 2010).

\section{RESULTS \\ TYROSINE PHOSPHORYLATION OF BONT LCS}

To understand structural and environmental factors affecting the stability of BoNT Lcs (Ahmed et al., 2001, 2003, 2004; Toth et al., 2009), we investigated in vitro tyrosine phosphorylation of LcA (including LcA424 and LcA420), LcB, LcC, LcD, LcE, and LcG by Src. Because purified LcF was not available to us, we could not investigate this light chain. Phosphorylation was monitored by Western blot probed with anti-phosphotyrosine antibody (Figure 1A). LcA, LcB, LcC, and LcG were rapidly phosphorylated within $3 \mathrm{~h}$. LcB and $\mathrm{LcG}$ phosphorylation reached a maximum within first $3 \mathrm{~h}$ of incubation, but intensity of the phosphorylated LcA band continued to increase with incubation time, probably because it had more than one phosphorylation site (see later). Bands of reacted $\mathrm{LcD}$ and $\mathrm{LcE}$, on the other hand, were very faint to undetectable, suggesting these Lc were not good substrates for phosphorylation by Src-kinase. Incubations of Lcs for up to $24 \mathrm{~h}$
Each sample was incubated with three units of $\mathrm{Src}$ for 3,7 , and $24 \mathrm{~h}$ at $30^{\circ} \mathrm{C}$. Unlabeled lanes on the far left left of each panel contain molecular mass marker proteins. (B) Coomassie staining of LcA420, LcA424, LcA-, LcA+, $L c B, L c G, L c C$, and $L c D$ after $24 \mathrm{~h}$ incubation are shown in this order on the right of molecular mass marker lane 2; LcA control is on the left, at lane 1.

did not appear to degrade the proteins by autocatalysis (Ahmed et al., 2003), as indicated by similar intensity of Coomassie-stained bands before and after incubation (Figure 1B). Long incubation times were chosen to ensure completion of the reactions of very low concentrations $(3 \sim 30 \mu \mathrm{M})$ of the Lc substrates employed in these experiments which could be much lower than their $K_{\mathrm{m}}$ for Src; a few cases where protein substrate $K_{\mathrm{m}}$ for Src was determined by others were in the millimolar range. Moreover, quantitative $\mathrm{k}_{\mathrm{cat}}$ value $(0.7 / \mathrm{s})$ available in literature for a Src places it as one of the poorest enzyme catalysts.

Two C-terminally truncated versions of LcA, both lacking a particular tyrosine residue, Y426, were included in our experiments. Like the full-length LcA the truncated versions, LcA420 and LcA424, were phosphorylated within $3 \mathrm{~h}$. To find out if an active site ligand would affect phosphorylation, we also included a competitive peptide inhibitor, CRATKML (Schmidt and Stafford, 2002) with the full-length LcA. The Western blot results (Figure 1A) could not differentiate the rate of phosphorylation from control by the inhibitor, although MS analyses (see later) clearly identified a reduction in phosphorylation.

ESI-MS analysis of time course samples indicated a progressive decrease in the molecular ion peak of unmodified LcB with concomitant increase in a molecular mass $80 \mathrm{Da}$ higher representing a single tyrosine residue phosphorylation. Similarly ESI-MS analysis of LcG and LcA reactions showed increasing molecular ion peaks 160 and $240 \mathrm{Da}$ greater (not shown) than unmodified Lc, characteristic for two and three tyrosine residue phosphorylations, respectively; this difference is most likely due to 1,2 , and multiple sites of phosphorylation in these three light chains respectively (see Table 2 , later). LcC1 showed an increase of $80 \mathrm{Da}$ for monophosphorylation, and a minor component for diphosphorylation. A representative spectrum of LcB-phos in Figure 2A, inset shows a gain of $2 \mathrm{amu}$ in the three peaks 

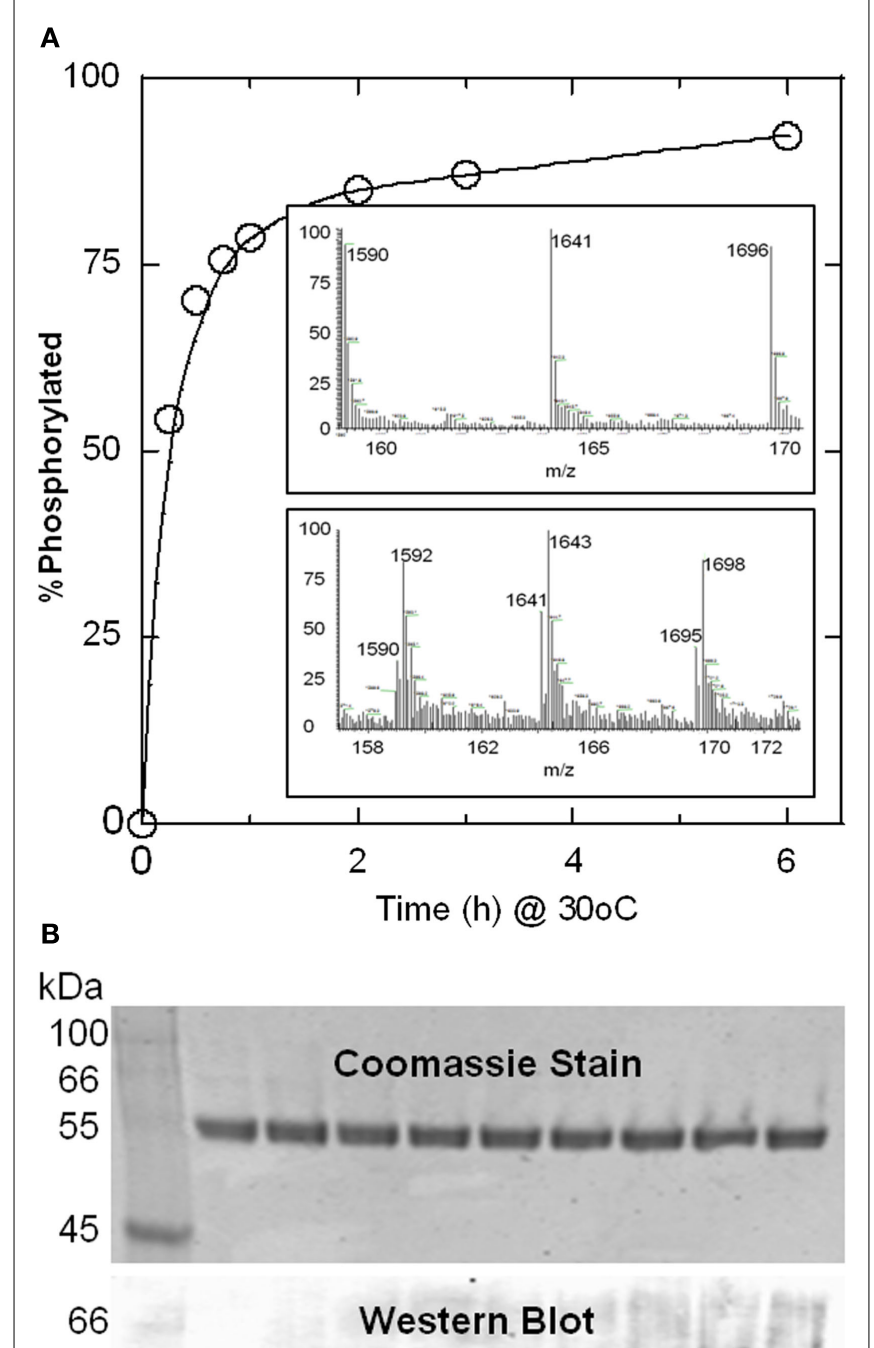

55

45

\section{$\begin{array}{llllllllll}1 & 2 & 3 & 4 & 5 & 6 & 7 & 8 & 9 & 10\end{array}$}

FIGURE 2 | Progress of Src-catalyzed phosphorylation of LcB as followed by mass spectrometry (A) anti-phosphotyrosine antibody

Western blot (B). (A) Relative abundance of the $\mathrm{m} / \mathrm{z}$ species representing phosphorylated LcB was plotted as a $\%$ of total LcB

(phosphorylated + unphosphorylated) as a function of time. Upper and lower panels in the inset show representative LC-ESI-MS spectra for the $\mathrm{LCB}$ phosphorylation reaction product at 0 and $4 \mathrm{~h}$, respectively, showing the $+32,+31$, and +30 ion peaks of $\operatorname{LcB}(1590,1641,1696)$, and $+32,+31$, and +30 ion peaks of LcB-phos corresponds to 1592, 1643, 1698, respectively. LC-ESI-MS was an effective tool to evaluate the degree of phosphorylation. Additionally, deconvolution of the ion peaks gave molecular weights for LcB as 50844.9 Da and for LcB-phos as 50922.0 indicating a single phosphorylated site. (B) Lanes 2-10 represent samples 0 , $0.25,0.5,0.75,1,2,3,6$, and $8 \mathrm{~h}$ after start of the phosphorylation reaction catalyzed by 0.5 units of Src. Lane 1 has molecular mass markers. Absence of the phosphorylated Src band (as seen in Figure 1A is due to much lower amount of $\mathrm{Src}(0.5$ units versus 3 units) used in this experiment. Because there were no detectable bands, the gel picture in (B) was truncated after $31 \mathrm{kDa}$ for better presentation.
(1590/1592, 1641/1643, and 1696/1698) from their unphosphorylated forms. The plot of the extent of phosphorylation versus time showed more than $90 \% \mathrm{LcB}$ was phosphorylated within $8 \mathrm{~h}$. Phosphorylation reaction of LcB when followed by Western blot also showed a similar time-dependent increase in intensity (Figure 2B). Similar results were also observed for LcA (see later.)

\section{SECONDARY AND TERTIARY STRUCTURES AND STABILITY}

To determine if phosphorylation affected secondary and tertiary structures of the LC, we collected CD and tryptophan fluorescence spectra, respectively. Because salts are known to affect protein structure and stability, we used two different buffers: $10 \mathrm{mM}$ Na-phosphate, $\mathrm{pH} 7.4$ and PBS, pH 7.4 containing physiological concentration $(0.85 \%)$ of $\mathrm{NaCl}$. We did not investigate LcD, LcE, LcA424, LcA420, and LcC430 because the first two did not show significant phosphorylation (Figure 1A), and the last three were truncated proteins. Far-UV CD spectra of LcA-phos, LcB-phos (Figure 3), and LcG-phos (not shown) remained essentially identical to the unphosphorylated forms between 200 and $260 \mathrm{~nm}$. Spectra were not affected by either $10 \mathrm{mM}$ phosphate buffer pH 7.4 or PBS (Figure 3). Spectra below $200 \mathrm{~nm}$ were more affected by the buffer composition than by phosphorylation. Similarly, the tryptophan fluorescence spectrum of LcA was not noticeably affected by phosphorylation (Figure 4). Tryptophan fluorescence spectrum of LcB-phos (not shown) was not different than its unphosphorylated form although fluorescence intensity was somewhat lower than that of LcB. These results suggested that both secondary and tertiary structures of LcA and LcB were not appreciably affected by phosphorylation. In contrast to our results, from FTIR DSC, and catalytic activity analyses, FerrerMontiel et al. (Encinar et al., 1998; Ibanez et al., 2004) reported $2-3^{\circ} \mathrm{C}$ increased thermostability of LcA-phos due to an increase in the helical content.

Post-translational modifications are known to affect protein stability (Li et al., 2002; Walsh, 2006b). We followed CD at $220 \mathrm{~nm}$ as a measure of thermostability when the temperature of the cuvette was continuously increased. Thermal denaturation profiles of LcA or LcB in $10 \mathrm{mM}$ phosphate buffer $\mathrm{pH} 7.4$ and of
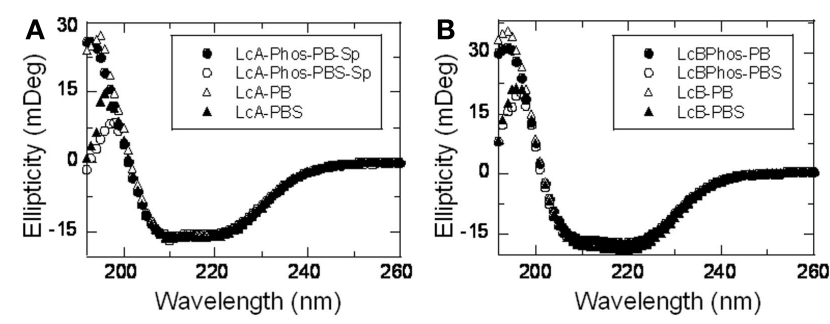

FIGURE 3 | Far-UV circular dichroism spectra of LcA-phos (A) and LcB-phos (B) compared with their unphosphorylated counterparts. Average of 5 scans at $20^{\circ} \mathrm{C}$ of each protein $(0.2 \mathrm{mg} / \mathrm{ml})$ in a $2 \mathrm{~mm}$ cuvette was recorded and reported here after subtraction of a corresponding buffer blank. Identity of each spectrum shown in the insets represent LcA-phos and LcB-phos in PB, closed circle; LcA-phos and LcB-phos in PBS, open circle; LcA and LcB in PB, open triangle; LcA and LcB in PBS, closed triangle. 


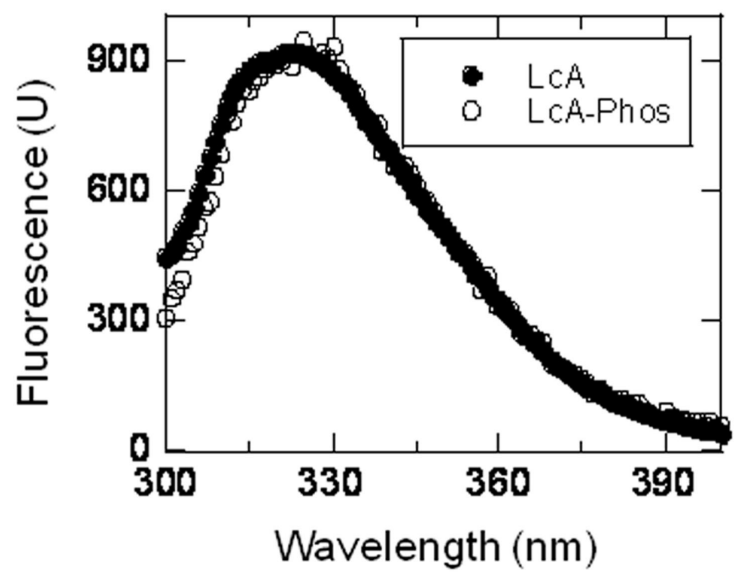

FIGURE 4 | Tryptophan fluorescence spectra of LcA-phos compared with its unpohsphorylated form. Average of five scans $\left(\lambda_{\mathrm{ex}}=295 \mathrm{~nm}\right)$ at $20^{\circ} \mathrm{C}$ of each protein $(0.02 \mathrm{mg} / \mathrm{ml})$ in a $2 \mathrm{~mm}$ cuvette was recorded and reported here after subtraction of a corresponding buffer blank. Identity of each spectrum shown in the inset represents LcA, closed circle and LcA-phos, open circle.
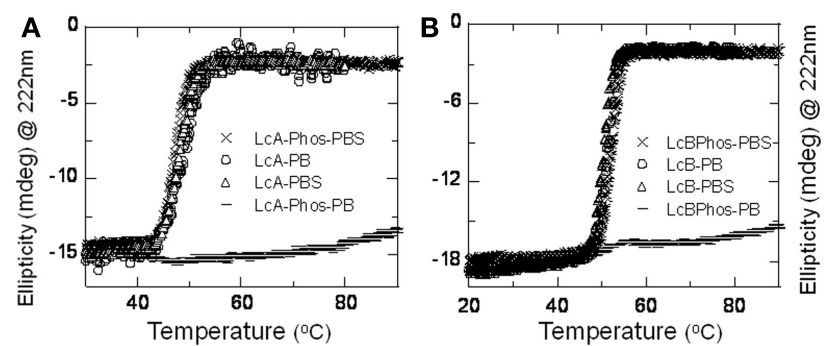

FIGURE 5 |Thermal denaturation patterns of LcA-phos $(A)$ and LcB-phos (B) are compared with those of their unphosphorylated counterparts in two different buffers. Circular dichroism signals at $222 \mathrm{~nm}$ of $0.18-0.2 \mathrm{mg} / \mathrm{ml}$ protein samples were monitored in at a temperature gradient of $1^{\circ} \mathrm{C} / \mathrm{min}$ from 20 to $90^{\circ} \mathrm{C}$. Symbols: LcA-phos and LcB-phos in PBS, X (crosx); LcA-phos and LcB-phos in PB, - (dashed line); LcA and LcB in PB, O (open circle); LcA and LcB in PBS, $\Delta$ (open triangle).

LcA-Phos or LcB-Phos in PBS underwent sharp, typical unfolding transitions (Figure 5) resulting in irreversible aggregate precipitate formation. Conversely, thermal denaturation profiles of LcA-Phos or LcB-Phos in $10 \mathrm{mM}$ phosphate buffer were significantly different and suggested resistance to unfolding. In addition, thermal denaturation in $100 \mathrm{mM}$ phosphate buffer $\mathrm{pH} 7.4$ (data not shown) exhibited the typical sharp transition forming irreversible aggregate precipitate. Results indicate cooperative irreversible aggregate formation in high buffer and salt concentrations that rapidly precipitates from solution. Thus, behavior of the phosphorylated proteins in low ionic strength buffer probably is an exception. The midpoint of thermal denaturation, $T_{\mathrm{m}}$ of LcAphos remained unchanged but those of LcB-phos and LcG-phos were $1-2^{\circ} \mathrm{C}$ higher than those of their unphosphorylated forms in PBS (Table 1).
Table 1 | Thermostability of phosphorylated BoNT Lc.

\begin{tabular}{lcc}
\hline Lc serotype & \multicolumn{2}{c}{$\begin{array}{l}\boldsymbol{T}_{\mathbf{m}}\left(^{\circ} \mathbf{C}\right) \text { - the midpoint of } \\
\text { thermal transition }\end{array}$} \\
\cline { 2 - 3 } & PBS & 10 mM Na-phosphate \\
\hline LcA & 47.9 & 48.7 \\
LcA-phos & 47.2 & - \\
LcB & 50.3 & 51.4 \\
LcB-phos & 52.1 & - \\
LcG & 53.5 & 55.3 \\
LcG-phos & 54.7 & 55.8
\end{tabular}

The midpoint of thermal transition, $T_{m}$, values were computed from Figure $\mathbf{5}$ and similar other traces not shown.

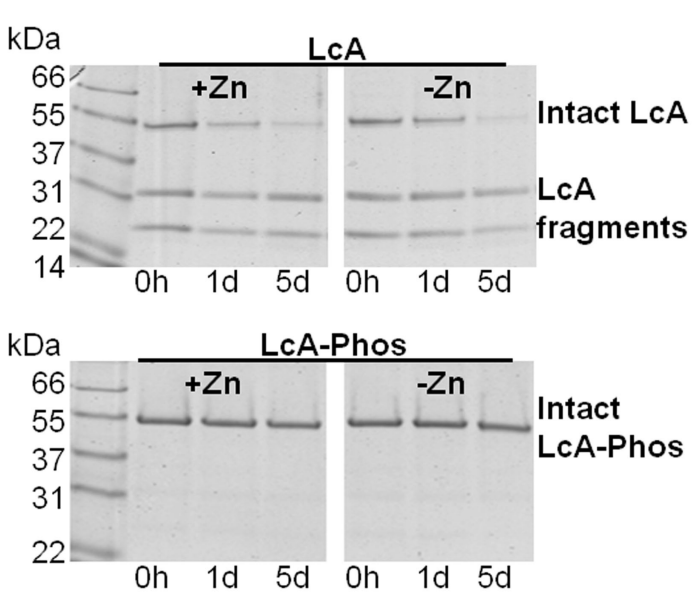

FIGURE 6 | Phosphorylation of LcA makes it highly resistant to autocatalysis. Purified LcA before (upper panels) and after (lower panels) the phosphorylation reaction was incubated without (right panels) or with (left panels) $0.25 \mathrm{mM} \mathrm{ZnCl}_{2}$ at $4^{\circ} \mathrm{C}$ for $0-5$ days (d). Aliquots were analyzed by SDS-PAGE and Coomassie staining. The LcA control at time zero represents the sample that was sitting at $4^{\circ} \mathrm{C}$ during the phosphorylation reaction, and until the start of the autocatalysis experiment. Thus, it shows substantial autocatalysis at time $0 \mathrm{~h}(\mathrm{~h})$. Lanes labeled $1 \mathrm{~d}$ and $5 \mathrm{~d}$ represent samples incubated for 1 and 5 days, respectively. Lane 1 in both panels have molecular mass markers (Mr).

\section{LCA AUTOCATALYSIS}

LcA is very prone to autocatalysis especially in the presence of divalent metal ions such as zinc, and increases with temperature leading to reduced catalytic activity (Ahmed et al., 2001, 2003 , 2004). We observed autocatalysis when the phosphorylation reaction mixture (that contained $\mathrm{MgCl}_{2}$ ) was incubated at $30-37^{\circ} \mathrm{C}$ (see Experimental Procedures). LcA catalytic activity was also greatly reduced by phosphorylation (see below). Because autocatalysis and catalysis of LcA occurs at the same active site (Ahmed et al., 2003), we were interested to know if the autocatalysis reaction would be affected by phosphorylation. When incubated at room temperature for 5 days in the presence of $\mathrm{ZnCl}_{2}$, most LcA fragmented but LcA-phos remained largely intact (Figure 6). Thus phosphorylation made the LcA resistant to autocatalysis. 
Table 2 | Src-catalyzed phosphorylation sites in LcA, LcB, LcC1, and LcG.

MSA* sequence

(Figure 7) \#
Corresponding tryptic sequence of phosphorylated peptides from

\begin{tabular}{|c|c|c|c|c|}
\hline & LcA & LcB & LcC1 & LcG \\
\hline 1 & & & & 69-DVY*EYYDPTYLK-80 \\
\hline 2 & 98-IY*STDLGR-105 & & 101-EIGEELIY*R-109 & \\
\hline 3 & 178-NGY*GSTQYIR-187 & & & \\
\hline 4 & & & 197-FMLTY* SNATNDVGEGR-212 & \\
\hline 5 & 245-VNTNAY*Y*EMSGLEVSFEELR-264 & & & \\
\hline 6 & 344-MLTEIY*TEDNFVK-356 & & & \\
\hline 7 & 365-TY*LNFDK-371 & & & \\
\hline 8 & 382-VNYTIY*D GFNLR-393 & ND & ND & ND \\
\hline 9 & 418-NFTGLFEFY*K-427 & 427-EHLAVY*K-433 & - & $\begin{array}{l}\text { 414-AVNKEAYEEISLEHLVIY* } \\
\text { R-432 }\end{array}$ \\
\hline
\end{tabular}

${ }^{*} \mathrm{MSA}$, multipple sequence alignment. Each phosphorylation reaction mixture contained $50 \mu \mathrm{g}$ LC. Tryptic digests of the $24 \mathrm{~h} 30^{\circ} \mathrm{C}$ phosphorylation reaction mixtures

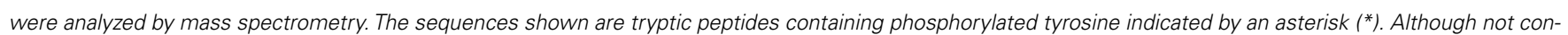

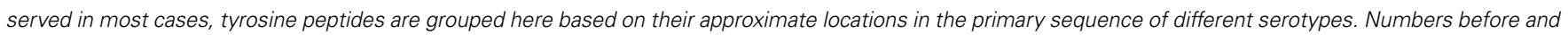

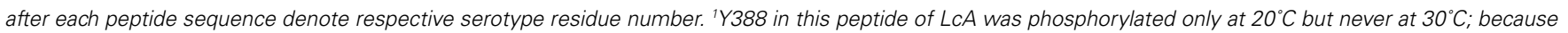

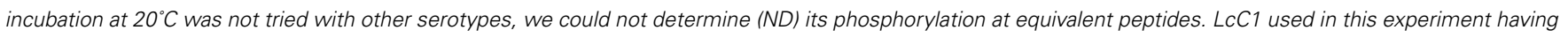
residues $1-430$ is missing a C-terminal Y431, and phosphorylation of this residue was not observed.

\section{PHOSPHORYLATION SITES}

We identified the sites of phosphorylation by mass spectrometric analyses of tryptic peptides. Three tyrosine residues in LcA, Y250, Y251, and Y426, were readily phosphorylated by Src (Tables 2 and 3). Tyrosines equivalent to Y250 and Y251 of LcA were not present in any other serotype.

The next predominant phosphorylated Y426 near the Cterminus (of the 449-residue LcA) is conserved in LcB, LcC1, and LcG, and was readily phosphorylated in LcB and LcG. The LcC1 protein used in this experiment was a truncated form (residues 1-430) lacking the C-terminus; this tyrosine (Y430) located at the end of the chain was not recognized by Src for phosphorylation.

The most predominant phosphorylation in the earliest time point samples of LcA was diphosphorylation at Y250Y251, followed by monophosphorylation of Y251 and monophosphorylation of Y426 (Table 3). Because monophosphorylation at Y251 but not at Y250 was observed, it is clear that reaction at the former led to phosphorylation of the latter residue. Thus the order of ease of phosphorylation was Y251 > Y250 > Y426. During some phosphorylation reactions, LcA degraded into two major fragments of approximately $23 \mathrm{kDa}$ containing Y251 and approximately $28 \mathrm{kDa}$ containing Y250. Only Y251 in the smaller fragment was phosphorylated. Y250-Y251 residues are found at the end of a flexible loop bordering the $\mathrm{S}^{\prime}$ substrate-binding pocket of LcA (Kumaran et al., 2008a) which also forms the most susceptible autocatalytic cleavable peptide bond (Ahmed et al., 2003).

Because the conserved Y72 residue in Figure 7 was reported to be the only Src-catalyzed phosphorylation site in BoNT Lcs (Encinar et al., 1998; Blanes-Mira et al., 2001; Ibanez et al., 2004), we repeated our experiment at least seven times with LcA under a variety of reaction conditions to determine if this residue was
Table 3 | Extent of phosphorylation of full-length and two C-terminally truncated LcA.

\begin{tabular}{lllll}
\hline $\begin{array}{l}\text { Tyrosine-phosphorylated } \\
\text { peptide sequence }\end{array}$ & LcA- & LcA+ & LcA424 & LcA420 \\
\hline 7-QFNYKDPVNGVDIAY*IK-23 & 0 & 0 & 0 & 4 \\
98- IY*STDLGR-105 & 16 & 19 & 0 & 0 \\
178-NGY*GSTOYIR-187 & 12 & 0 & 0 & 0 \\
232-LY*GIAINPNR-241 & 0 & 26 & 22 & 15 \\
245- & $63(17)$ & $54(6)$ & $86(7)$ & $86(3)$ \\
VNTNAY*Y*EMSGLEVSFEELR- & & & & \\
264 & & & & \\
344-MLTEIY*TEDNFVK-356 & 9 & 13 & 0 & 0 \\
365-TY*LNFDK-371 & 4 & 5 & 0 & 0 \\
$418-N F T G L F E F *^{*}$ K-427 & 19 & 0 & - & - \\
\hline
\end{tabular}

Each phosphorylation reaction mixture contained $50 \mu \mathrm{g}$ Lc. Tryptic digests of the $24 \mathrm{~h}, 30^{\circ} \mathrm{C}$ phosphorylation reaction mixtures were analyzed by LC-MS. The sequences shown are those tryptic peptides that contained phosphorylated tyrosine indicated by an asterisk $(*)$. $L C A-$ and $L C A+$ represent Src reaction mixtures that were incubated without and with $(0.2 \mathrm{mM})$, respectively, of an active site competitive inhibitor, CRATKML. The numbers in the right 4 columns represent $\%$ of the tyrosine residue that was phosphorylated. These $\%$ values were computed from area of $L c$ peaks of phosphorylated and native peptides. The numbers in parentheses indicate mono phosphorylation state (\%) of Y251.

phosphorylated. Instead, we found several other minor phosphorylation sites: Y99, Y180, Y349, and Y366 (Tables 2 and 3). Of these residues, only Y366 is fully conserved (Figure 7) but it was phosphorylated only in LcA although there are five more (Y72, Y73, Y77, Y321, Y366, and Y384, LcA numbering) conserved residues. 


\begin{tabular}{|c|c|c|c|c|c|c|c|}
\hline \multicolumn{6}{|c|}{ Aligned Sequence \#1 } & \multicolumn{2}{|c|}{ Aligned } \\
\hline $\operatorname{LCA}$ & 67 & \multicolumn{2}{|c|}{ QVPV-SYYDSTYLSTDNEKDN } & 86 & LCA & \multicolumn{2}{|c|}{94 LFERIYS } \\
\hline $\operatorname{LcB}$ & 67 & \multicolumn{2}{|c|}{ NRDVCEYYDPD YLNTNDKKNI } & 87 & $\mathrm{LcB}$ & \multicolumn{2}{|c|}{ LFNRIKS } \\
\hline $\operatorname{LeC} 1$ & 66 & \multicolumn{2}{|c|}{ SPKS-GYYDPNYLSTDSDKDT } & 85 & $\operatorname{LcC} 1$ & \multicolumn{2}{|c|}{ LF KR INS } \\
\hline $\operatorname{LCD}$ & 66 & \multicolumn{2}{|c|}{ SKYQ-SYYDPSYLSTDEQKDT } & 85 & $\mathrm{LCD}$ & \multicolumn{2}{|c|}{ LFKRINE } \\
\hline $\operatorname{LcE}$ & 63 & \multicolumn{2}{|c|}{ NGDS-SYYDPNYLQSDEEKDR } & 82 & $\mathrm{LCE}$ & \multicolumn{2}{|c|}{ IFNR INN } \\
\hline LcF & 67 & \multicolumn{2}{|c|}{ NGSS-AYYDPNYLTTDAEKDR } & 86 & LcF & $94 \mathrm{LFK}$ & KRINS: \\
\hline $\operatorname{LcG}$ & 67 & \multicolumn{2}{|c|}{7 SKDVYEYYDPTYLKTD AEKDK } & 87 & $\operatorname{LcG}$ & $95 \mathrm{~L}$ & RINS \\
\hline \multicolumn{6}{|c|}{ Aligned Sequence \#3 } & \multicolumn{2}{|c|}{ Aligned } \\
\hline LCA & \multicolumn{3}{|c|}{172 VLN-----LTRNGYGSTQYIR } & 187 & $\operatorname{LcX}$ & \\
\hline $\mathrm{LcB}$ & \multicolumn{3}{|c|}{$1 7 9 \longdiv { \mathrm { NHF } - - - - - \text { ASREGFGGIMQMK } }$} & 194 & $\operatorname{LcB}$ & \multicolumn{2}{|c|}{ FCPEYVS } \\
\hline $\operatorname{LeC} 1$ & 177 & NNT--- F M MQEGFG & ALSIIS & 193 & $\operatorname{LeC} 1$ & 193 ISP & RFML \\
\hline $\mathrm{LcD}$ & 177 & QQS----NPSFEGFG & TLSILK & 193 & $\mathrm{LCD}$ & $194 \overline{\mathrm{VAF}}$ & EFLL \\
\hline $\mathrm{LCE}$ & 169 & NN----YMPSNHGFG & SIAIVT & 185 & $\mathrm{LcE}$ & 186 FSP & EYSF \\
\hline $\mathrm{LcF}$ & 174 & MDSGGVYDPSNDGFG & SIN IVT & 194 & LeF & $195 \mathrm{FSF}$ & EEY \\
\hline $\operatorname{LcG}$ & 179 & GHS-----PISEGFG & ARMMIR & 194 & $L c G$ & $195 \mathrm{FCP}$ & SCLN \\
\hline Aligr & ned & Sequence \#5 & & & & Alis & ned \\
\hline $\mathrm{LCA}$ & 245 & VNT-NAYYEMSGLEV & SFEELR & 264 & $\operatorname{Lcd}$ & $337 \mathrm{KFD}$ & $\mathrm{KLYK}$ \\
\hline $\operatorname{LcB}$ & 251 & PNE-KKFFMQSTD A I & QAEELY & 270 & $\mathrm{LcB}$ & $344 \overline{\mathrm{SFD}}$ & KLYK \\
\hline $\operatorname{LeC} 1$ & 251 & SVTSNIF YSQYNVKL & EYAEIY & 271 & $\operatorname{LcC} 1$ & $346 \mathrm{KF}$ & $\mathrm{LY}$ \\
\hline $\mathrm{LCD}$ & 251 & PQVSEGFFSQDGPNV & QFEELY & 271 & $\mathrm{LCD}$ & $346 \mathrm{KFI}$ & $\mathrm{LY}$ \\
\hline $\operatorname{LcE}$ & 234 & TQK-QNPL ITNIRGT & NIEEFL & 253 & LeE & 323 & \\
\hline $\mathrm{LcF}$ & 249 & KVK-QAPLMIÄEKP I & RLEEFL & 268 & $\mathrm{LcF}$ & $340 \mathrm{KFN}$ & IY \\
\hline $\operatorname{LcG}$ & 251 & PNT-KEFFMQHSDPV & QÄEELY & 270 & $\operatorname{LcG}$ & $343 \mathrm{KF}$ & KLYK \\
\hline Aligr & ned & Sequence \#7 & & & & Alic & ned \\
\hline $\mathrm{LCA}$ & 364 & KTYLNFDK- ¿NVF KIN & IIVP KVN & 383 & $\operatorname{LcX}$ & $381 \mathrm{KVN}$ & YTIY \\
\hline $\mathrm{LcB}$ & 371 & ASYFSDSLPPVKIKN & ILLDNE I & 391 & $\mathrm{LcB}$ & $389 \widehat{\mathrm{NEI}}$ & YTIE \\
\hline $\operatorname{LeC} 1$ & 373 & KIYLSNVYTPVTMN- & ILDDNV & 392 & $\operatorname{LeC} 1$ & $390 \mathrm{DNV}$ & YD I \\
\hline $\mathrm{LcD}$ & 373 & THYFSRHYLPVF MN- & ILDDNI & 392 & $\mathrm{LCD}$ & $390 \mathrm{DNI}$ & YTI \\
\hline $\operatorname{LcE}$ & 349 & QTY IGQYK-YF KLSN & ILLNDSI & 368 & $\operatorname{LcE}$ & 366 DSI & I YNI \\
\hline LeF & 366 & NTYF IKYG-F L KVPN & ILLDDD I & 385 & $\mathrm{LcF}$ & 383 DDI & IYTV \\
\hline $\mathrm{LeG}$ & 370 & YSYFSEYLPPIKTEK & LLDNTI & 390 & $\mathrm{LcG}$ & $388 \mathrm{NTI}$ & 1112 \\
\hline & & Alig & nea se & & & & \\
\hline & & Les & $413 \mathrm{~F}$ & $\mathrm{LKNN}$ & FEFYY & LL-CVR3 & 433 \\
\hline & & $\mathrm{LcB}$ & $421 \overline{\mathrm{YE}}$ & EISK- & $\mathrm{AV}-\mathrm{YK}$ & IQMCKSV & 440 \\
\hline & & $\mathrm{LcC} 1$ & $422 \overline{\mathrm{RF}}$ & $\mathrm{NNPE}$ & YLFTK & $\mathrm{F}--\mathrm{CHKi}$ & 440 \\
\hline & & $\mathrm{LCD}$ & $422 \mathrm{QH}$ & LSSE- & DLFTK & $\mathrm{V}--\mathrm{CLRL}$ & 440 \\
\hline & & $\operatorname{LcE}$ & $396 \mathrm{II}$ & PITG- & VKKI I & $\mathrm{RF}-\mathrm{CKN}-$ & 414 \\
\hline & & $\mathrm{LcF}$ & 413 II & SIPD- & VEKIV & $\mathrm{KF}-\mathrm{CKS}-$ & 431 \\
\hline & & $\mathrm{LcG}$ & $420 \mathrm{EE}$ & ISLE- & $I--Y R$ & IAMCKPV & 439 \\
\hline
\end{tabular}

FIGURE 7 | Multiple sequence alignment (MSA) of conserved and non-conserved tyrosine containing peptides that were

tyrosine-phosphorylated by Src. Clustal multiple sequence alignment of all of $\sim 450$ residues of subtype 1 of BoNT Lc sequences were

constructed. Only those stretches of the sequence alignment are shown here that contained a tyrosine residue being phosphorylated (bold) in any serotype sequence (underlined) by Src in our experiments. Because of high degeneracy, the sequence number 9 was also manually adjusted by keeping the identical cysteine fixed and the phosphorylated tyrosine aligned. GenBank ID: LcA1: AAQ06331; LcB1:BAE48264; LcC1: CAA44263; LcD1: AAB24244; LcE1: BAB86845; LcF1:ADA79551; LcG: CAA52275.
Thus, some conserved tyrosine residues although were phosphorylated in one (see later) serotypes, remained unaffected in other serotypes. Our results provide a generalized picture of preferential tyrosine phosphorylation across the BoNT serotypes but did not show a pattern of consistency for in vitro phosphorylation across different serotypes.

In another experiment where LcA was incubated at $20^{\circ} \mathrm{C}$ for $24 \mathrm{~h}, 85 \%$ of Y250-Y251 was diphosphorylated, 15\% of Y250, $21 \%$ of Y426, and 15\% of Y387 was phosphorylated. Please note that $\mathrm{Y} 387$ was not phosphorylated at $30^{\circ} \mathrm{C}$ (Table 2). Addition of $0.05 \%$ Tween-20 to this reaction mixture almost completely abolished Y250-Y251 diphosphorylation but increased Y251, and Y426 monophosphorylations to 70 and 38\%, respectively, while decreased Y387 phosphorylation to 7\%. Thus, it appears that temperature and detergents like Tween-20 can change the LcA conformation in exposing new tyrosine residues and their availability for phosphorylation by Src. We did not investigate the effects of temperature and detergent with other Lc serotypes.

Interestingly, only one residue Y432 in LcB (corresponding to Y426 in LcA) (Figure 7) was rapidly phosphorylated. Its equivalent in LcG, Y431, was also readily phosphorylated. Another non-conserved residue in LcG, Y71, also reacted but measuring the corresponding mass peaks at all time points, showed that its phosphorylated form was always much lower than the corresponding Y431; after $24 \mathrm{~h}$ of incubation, $78 \%$ of Y $430,18 \%$ of Y71, and $25 \%$ of both were phosphorylated.

From the preceding results, tyrosine residue 3-6 positions upstream from the essential and conserved disulfide-forming cysteine (C430 in LcA, C437 in LcB, and C436 in LcG) appears to be 
the only common residues in most of the BoNT serotypes that are phosphorylated by Src. Although present in $\mathrm{LcCl}$ native sequence as Y431, it was absent in our LcC1 construct (residues 1-430). We suspect this residue in full-length $\mathrm{LcCl}$ would be as susceptible to Src-catalyzed phosphorylation as in LcA, LcB, and LcG. This tyrosine residue readily gets phosphorylated in $\mathrm{LcB}$ and $\mathrm{LcG}$ but much slower in LcA.

\section{ROLE OF C-TERMINUS OF LCA ON CATALYTIC ACTIVITY}

The C-terminus of LcA undergoes autocatalytic processing (Ahmed et al., 2001), and C-terminally truncated LcA has reduced catalytic activity (Baldwin et al., 2004), suggesting that the Cterminus approaches the active site in solution (Ahmed et al., 2003). We therefore included two C-terminally truncated LcA (both lacking Y426) and a competitive inhibitor with full-length LcA in the Src reactions to determine the effect on phosphorylation of other tyrosines (Table 3). Three important results were obtained. First, the competitive inhibitor CRATKML (Schmidt and Stafford, 2002) inhibited phosphorylation of Y426 at the Cterminus and of Y180. Second, no measurable phosphorylations of Y199, Y180, Y349, and Y366 were detected in the C-terminally truncated Lcs (Table 3). Third, addition of the inhibitor with fulllength LcA and truncation of C-terminal residues beyond 420 exposed a new Y233 to phosphorylation. These results strongly support the earlier suggestion that the C-terminus interacts with the active site (Ahmed et al., 2003; Baldwin et al., 2004). In addition, interactions of the C-terminus with other parts of the protein must induce subtle changes in the protein's conformation so that some tyrosine residues become exposed to Src-catalyzed phosphorylation. Like Y366, Y233 is also a conserved residue but this too was not phosphorylated in any other serotype.

\section{CATALYTIC ACTIVITY OF PHOSPHORYLATED LCA AND LCB}

We assayed LcA and LcB catalytic activities as a function of phosphorylation. Aliquots of the phosphorylation reaction mixtures were removed at set times for catalytic activity measurements and for assessing the extent of phosphorylation. LcA catalytic activity was significantly decreased but LcB activity appeared to be slightly stimulated by increased phosphorylation (Figure 8). The LcB catalytic activity was stable for at least 4 weeks when stored at $4^{\circ} \mathrm{C}$. Loss of LcA activity in the phosphorylation reaction mixture (Figure 8) was verified in a purified preparation. At the end of $48 \mathrm{~h}$ incubation at $20^{\circ} \mathrm{C}$, un-reacted components of the reaction mixture were first removed by anti-Src affinity precipitation followed by repeatedly washing the LcA-phos on a Centricon10 microconcentrator. As seen before (Table 1), ESI-MS of the tryptic digests of the purified sample identified Y250-Y251 as the major phosphorylation site along with Y426 as another prominent phosphorylation site.

Loss of activity of the LcA-phos was measured in the purified sample as due to effects of phosphorylation on both $K_{\mathrm{m}}$ and $K_{\text {cat }}$ (Figure 9). Because phosphorylation had little impact on the LcB catalytic activity (Figure 8B), we did not attempt to determine its kinetic parameters. Although we prepared a large amount of LcG (see above), we could not determine its catalytic activity, due to the lack of a dependable assay method.

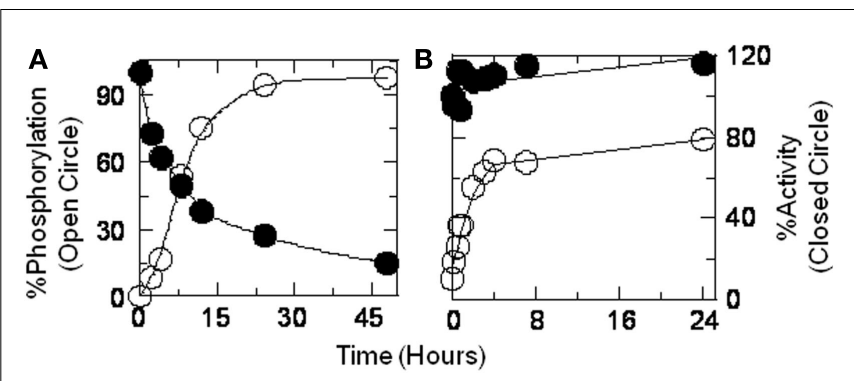

FIGURE 8 | Catalytic activities (closed circle) of LcA (A) and LcB (B) are compared to the extent of phosphorylation (open circle) as a function of phosphorylation incubation time. Aliquots of the reaction mixtures were immediately diluted with substrate for activity measurements, SDS-PAGE loading buffer for Western blot, and with TFA for mass spectrometric analyses. Phosphorylation of LcA was computed by densitometric scanning of the Western blot images of $\mathrm{Src}$ reaction mixture $\left(20^{\circ} \mathrm{C}\right)$ aliquots at various time intervals. Phosphorylation of $\operatorname{LCB}\left(30^{\circ} \mathrm{C}\right)$ was computed from the ratio of phosphorylated to non-phosphorylated ionic mass peaks. A low temperature of $20^{\circ} \mathrm{C}$ necessitated a longer incubation of LcA for completion of the phosphorylation reaction.

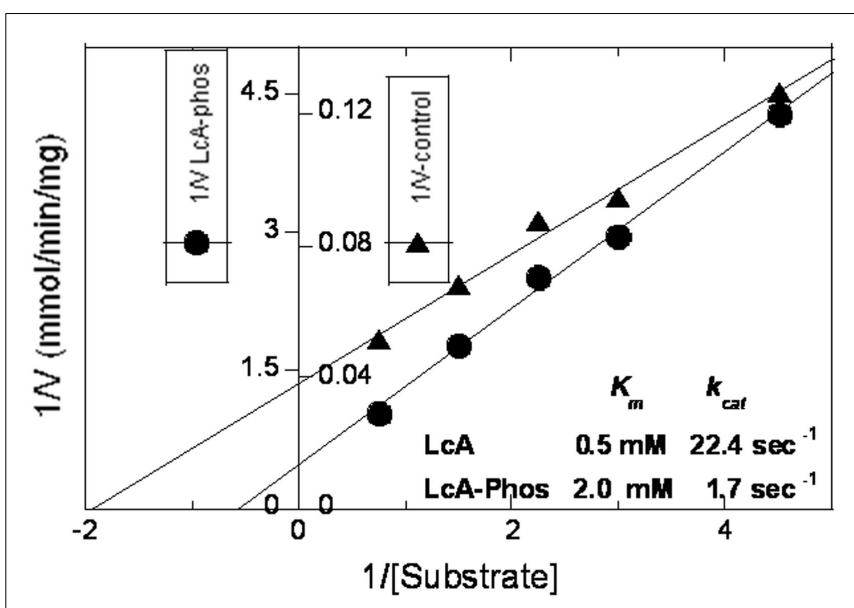

FIGURE 9 | Lineweaver-Burke plots of reaction velocity versus substrate concentration of reactions catalyzed by phosphorylated (closed circles) versus unphosphorylated (closed triangles) LcA. The $30-\mu l$ assay reaction mixtures contained $5 \mathrm{mM}$ dithiothreitol, $0.25 \mathrm{mM}$ $\mathrm{ZnCl}_{2}, 0.2 \mathrm{mg} / \mathrm{ml} \mathrm{BSA}, 0.028 \mathrm{mg} / \mathrm{ml}$ LcA, or $0.45 \mathrm{mg} / \mathrm{ml}$ LcA-phos and variable $(0.22,0.33,0.44,0.67$, and $1.13 \mathrm{mM})$ substrate

(SNKTRIDEANQ-RATKML) concentrations in $50 \mathrm{mM} \mathrm{Na-HEPES} \mathrm{pH} \mathrm{7.4.} \mathrm{The}$ $y$-axis has two scales, one for LcA (inner scale, closed triangle), and the other for LcA-phos (outer scale, closed circle). Each data point represents an average of five assays.

\section{DISCUSSION}

A major challenge in the development of therapeutics as medical intervention to botulinum BoNT intoxication is the persistence of clinical symptoms for certain serotypes, particularly BoNT/A,/B, and/C compared to the short-lived/E (Adler et al., 2001; Foran et al., 2003). For example, half-life of BoNT/A action in rat cerebellar neurons was 31 days, for BoNT/B was 10 days, and for BoNT/E it was less than 1 day (Foran et al., 2003). Besides, after 15 days 
of start of intoxication, only $12 \%$ recovery was achieved from BoNT/A-induced rat muscle paralysis compared to $94 \%$ recovery of BoNT/E-induced paralysis (Adler et al., 2001). Because the reaction mechanism and overall three-dimensional structure of all BoNT catalytic domains are essentially identical (Lacy et al., 1998; Eswaramoorthy et al., 2002; Agarwal et al., 2004, 2005; Swaminathan et al., 2004; Arndt et al., 2005, 2006; Jin et al., 2007; Kumaran et al., 2008a), it was expected that the proteins might undergo sequence-dependent covalent modification inside animal host cells.

Of all the post-translational protein modifications, phosphorylation is probably the most common and also most extensively studied (Walsh, 2006b). In addition to playing a central role in protein-based signaling pathways, phosphorylation can impart a proteins' stabilization (Li et al., 2002) and stimulation of activity (Patwardhan and Miller, 2007). We investigated if (a) phosphorylation can occur in the catalytic domains of various serotypes of BoNTs, and (b) if differences in their phosphorylation patterns might correlate with differences in their persistence of their catalytic activity inside neurons.

In this study, we employed tyrosine kinase Src as the phosphorylating enzyme. Ferrer-Montiel et al. (1996) had reported that only tyrosine kinase Src and no other serine-threonine kinases were effective for BoNT/A phosphorylation. We showed that, with the exception of $\mathrm{LcD}$ and $\mathrm{LcE}$, tyrosine residues in other BoNT Lcs were rapidly phosphorylated by Src (Figure 1A; Table 2). Although we did not detect any phosphorylation of LcE, the results remain inconclusive because the concentration of LcE was very low due to its poor solubility. Our results differ with previous reports concerning phosphorylation of the invariant Y71 of LcA (our numbering Y72) and Y67 of LcE (Encinar et al., 1998; BlanesMira et al., 2001; Ibanez et al., 2004). Because this residue was reported as the only Src-catalyzed BoNT Lc phosphorylation site based on mutational studies with LcA and LcE (Encinar et al., 1998; Blanes-Mira et al., 2001; Ibanez et al., 2004), we repeated our experiments several times with LcA and LcB but could not detect Y71 (our numbering Y72) phosphorylation using trypsin digestion of the phosphorylated Lc and mass spectrometry. In our studies, both conserved and non-conserved (Figure 7) tyrosines of LcA were phosphorylated (Tables 2 and 3 ) but no conserved tyrosine was phosphorylated across the serotypes.

From the available data, phosphorylation of Y426 of LcA, Y432 of LcB, and of Y431 of LcG may have some functional significance because they are located very near the fully conserved C430 (of LcA) that is essential for translocation (Simpson et al., 2004). For example, wherever conserved, this residue was readily phosphorylated: Y432 of LcB and Y431 of LcG. Additional studies are needed to ascertain the significance of phosphorylation of this residue.

\section{REFERENCES}

Adler, M., Keller, J. E., Sheridan, R.

E., and Deshpande, S. S. (2001).

Persistence of botulinum neurotoxin A demonstrated by sequential administration of serotypes $\mathrm{A}$ and $\mathrm{E}$ in rat EDL muscle. Toxicon 39, 233-243.

\section{CONSEQUENCE OF TYROSINE PHOSPHORYLATION}

The in vitro phosphorylation results described here do not support any detectable change in the protein's secondary or tertiary structure, nor any significant impact on their thermal stability. Slightly elevated $\left(1 \sim 2^{\circ} \mathrm{C}\right)$ midpoint of thermal transition (Figure 5; Table 1) and activity of LcB (Figure 8B) and dramatic reduction in LcA activity (Figures 7,8 ) by our in vitro tyrosine phosphorylation experiments (Figures 1, 2; Tables 2, 3) are in contradiction to the well-established, increased catalytic stability of BoNT/A over BoNT/B in neuronal cells (Keller et al., 1999; Foran et al., 2003). From a structural point, the increased $K_{\mathrm{m}}$ and decreased $k_{\text {cat }}$ of LcA-phos (Figure 9) can be easily explained by the fact that phosphorylation of Y250 and Y251 introduces two bulky groups on the 250-loop that normally closes onto the active site during catalysis (Kumaran et al., 2008b). This may limit the access of the substrate to the active site. Because no ex vivo quantitative specific activity data are available, one cannot be sure if LcA activity is low inside neurons that would support our in vitro data (Figure 8), even though LcA activity persists there for a very long time (Keller et al., 1999; Foran et al., 2003). Because LcB does not have a site near the active site that can be phosphorylated, the LcB activity remained little affected by phosphorylation. This consideration of steric hindrance by phosphate will equally explain the stability of LcA-phos from autocatalytic fragmentation (Figure 6) that occurs at the LcA active site (Ahmed et al., 2003, 2008).

\section{CONCLUSION}

In vitro reaction of $\mathrm{LcA}, \mathrm{LcB}, \mathrm{LcC} 1, \mathrm{LcD}, \mathrm{LcE}$, and $\mathrm{LcG}$ with Tyrosine kinase Src resulted in phosphorylation of several tyrosine residues. One of these residues is fully conserved but not all the conserved tyrosine residues were phosphorylated in each serotype. Phosphorylation of Y250 and Y251 in LcA took place most readily and made the protein highly resistant to autocatalysis but drastically reduced its catalytic efficiency. Phosphorylation of the tyrosine residue located near to the essential, conserved cysteine residue ( $\mathrm{C} 430$ of $\mathrm{LcA}$ ) might have a functional significance for LcA, LcB, LcC1, and LcG.

\section{ACKNOWLEDGMENTS}

We thank Mr. Matthew Ludivico for conducting the UPLC ${ }^{\mathrm{TM}}$ analyses, kinetic and circular dichroism experiments, and Dr. Mizanur Rahman for careful reading of the manuscript. This project received support from the Defense Threat Reduction Agency-Joint Science and Technology Office for Chemical and Biological Defense (Grant \#s CBS.MEDBIO.01.10.RD.002 and JSTOCBD3.10012_06_RD_B to S. Ashraf Ahmed). Opinions, interpretations, conclusions, and recommendations are those of the author and are not necessarily endorsed by the U.S. Army.

Swaminathan, S. (2004). Structural analysis of botulinum neurotoxin type $\mathrm{E}$ catalytic domain and its mutant Glu212 $\rightarrow$ Gln reveals the pivotal role of the Glu212 carboxylate in the catalytic pathway. Biochemistry 43, 6637-6644.
Agarwal, R., Schmidt, J. J., Stafford, R. G., and Swaminathan, S. (2009). Mode of VAMP substrate recognition and inhibition of Clostridium botulinum neurotoxin F. Nat. Struct. Mol. Biol. 16, 789-794.

Ahmed, S. A., Byrne, M. P., Jensen, M., Hines, H. B., Brueggemann, E., 
and Smith, L. A. (2001). Enzymatic autocatalysis of botulinum A neurotoxin light chain. J. Protein Chem. 20, 221-231.

Ahmed, S. A., Ludivico, M. L., and Smith, L. A. (2004). Factors affecting autocatalysis of botulinum A neurotoxin light chain. Protein J. 23, 445-451.

Ahmed, S. A., McPhie, P., and Smith, L. A. (2003). Autocatalytically fragmented light chain of botulinum a neurotoxin is enzymatically active. Biochemistry 42, 12539-12549.

Ahmed, S. A., Olson, M. A., Ludivico, M. L., Gilsdorf, J., and Smith, L. A. (2008). Identification of residues surrounding the active site of type A botulinum neurotoxin important for substrate recognition and catalytic activity. Protein J. 27, 151-162.

Ahmed, S. A., and Smith, L. A. (2000). Light chain of botulinum A neurotoxin expressed as an inclusion body from a synthetic gene is catalytically and functionally active. J. Protein Chem. 19, 475-487.

Arndt, J. W., Chai, Q., Christian, T., and Stevens, R. C. (2006). Structure of botulinum neurotoxin type $\mathrm{D}$ light chain at 1.65 A resolution: repercussions for VAMP-2 substrate specificity. Biochemistry 45, 3255-3262.

Arndt, J. W., Yu, W., Bi, F., and Stevens, R. C. (2005). Crystal structure of botulinum neurotoxin type $\mathrm{G}$ light chain: serotype divergence in substrate recognition. Biochemistry 44, 9574-9580.

Arnon, S. S., Schechter, R., Inglesby, T. V., Henderson, D. A., Bartlett, J. G., Ascher, M. S., Eitzen, E., Fine, A. D., Hauer, J., Layton, M., Lillibridge, S., Osterholm, M. T., O’Toole, T., Parker, G., Perl, T. M., Russell, P. K., Swerdlow, D. L., and Tonat, K. (2001). Botulinum toxin as a biological weapon: medical and public health management. JAMA 285, 1059-1070.

Baldwin, M. R., Bradshaw, M., Johnson, E. A., and Barbieri, J. T. (2004). The C-terminus of botulinum neurotoxin type A light chain contributes to solubility, catalysis, and stability. Protein Expr. Purif. 37, 187-195.

Blanes-Mira, C., Ibanez, C., FernandezBallester, G., Planells-Cases, R., Perez-Paya, E., and Ferrer-Montiel, A. (2001). Thermal stabilization of the catalytic domain of botulinum neurotoxin $\mathrm{E}$ by phosphorylation of a single tyrosine residue. Biochemistry 40, 2234-2242.

Burnett, J. C., Wang, C., Nuss, J. E., Nguyen, T. L., Hermone, A. R.,
Schmidt, J. J., Gussio, R., Wipf, P., and Bavari, S. (2009). Pharmacophoreguided lead optimization: the rational design of a non-zinc coordinating, sub-micromolar inhibitor of the botulinum neurotoxin serotype a metalloprotease. Bioorg. Med. Chem. Lett. 19, 5811-5813.

Capkova, K., Salzameda, N. T., and Janda, K. D. (2009). Investigations into small molecule non-peptidic inhibitors of the botulinum neurotoxins. Toxicon 54, 575-582.

Cochrane, R. C. (1947). "Biological warfare research in the United States," in History of the Chemical Warfare Service in World War II (01 July 1940 - 15 August 1945). Fort Detrick: Office of Chief, Chemical Corps.

Encinar, J. A., Fernandez, A., Ferragut, J. A., Gonzalez-Ros, J. M., DasGupta, B. R., Montal, M., and FerrerMontiel, A. (1998). Structural stabilization of botulinum neurotoxins by tyrosine phosphorylation. FEBS Lett. 429, 78-82.

Eswaramoorthy, S., Kumaran, D., and Swaminathan, S. (2002). A novel mechanism for Clostridium botulinum neurotoxin inhibition. Biochemistry 41, 9795-9802.

Ferrer-Montiel, A. V., Canaves, J. M., DasGupta, B. R., Wilson, M. C., and Montal, M. (1996). Tyrosine phosphorylation modulates the activity of clostridial neurotoxins. J. Biol. Chem. 271, 18322-18325.

Ferrer-Montiel, A. V., Gutierrez, L. M., Apland, J. P., Canaves, J. M., Gil, A., Viniegra, S., Biser, J. A., Adler, M., and Montal, M. (1998). The 26mer peptide released from SNAP-25 cleavage by botulinum neurotoxin $\mathrm{E}$ inhibits vesicle docking. FEBS Lett. 435, 84-88.

Foran, P., Shone, C. C., and Dolly, J. O. (1994). Differences in the protease activities of tetanus and botulinum B toxins revealed by the cleavage of vesicle-associated membrane protein and various sized fragments. Biochemistry 33, 15365-15374.

Foran, P. G., Mohammed, N., Lisk, G. O., Nagwaney, S., Lawrence, G. W., Johnson, E., Smith, L., Aoki, K. R., and Dolly, J. O. (2003). Evaluation of the therapeutic usefulness of botulinum neurotoxin $\mathrm{B}, \mathrm{C} 1, \mathrm{E}$, and $\mathrm{F}$ compared with the long lasting type A. Basis for distinct durations of inhibition of exocytosis in central neurons. J. Biol. Chem. 278, 1363-1371.

Foster, L. J., Yeung, B., Mohtashami, M., Ross, K., Trimble, W. S., and Klip, A. (1998). Binary interactions of the SNARE proteins syntaxin-4,
SNAP23, and VAMP-2 and their regulation by phosphorylation. Biochemistry 37, 11089-11096.

Gill, D. M. (1982). Bacterial toxins: table of lethal amounts. Microbiol. Rev. 46, 86-94.

Gilsdorf, J., Gul, N., and Smith, L. A. (2006). Expression, purification, and characterization of Clostridium botulinum type B light chain. Protein Expr. Purif. 46, 256-267.

Hale, M., Oyler, G., Swaminathan, S., and Ahmed, S. A. (2011). Basic tetrapeptides as potent intracellular inhibitors of type A botulinum neurotoxin protease activity. J. Biol. Chem. 286, 1802-1811.

Hines, H. B., Kim, A. D., Stafford, R. G., Badie, S. S., Brueggeman, E. E., Newman, D. J., and Schmidt, J. J. (2008). Use of a recombinant fluorescent substrate with cleavage sites for all botulinum neurotoxins in high-throughput screening of natural product extracts for inhibitors of serotypes A, B, and E. Appl. Environ. Microbiol. 74, 653-659.

Ibanez, C., Blanes-Mira, C., FernandezBallester, G., Planells-Cases, R., and Ferrer-Montiel, A. (2004). Modulation of botulinum neurotoxin A catalytic domain stability by tyrosine phosphorylation. FEBS Lett. 578, 121-127.

Jensen, M. J., Smith, T. J., Ahmed, S. A., and Smith, L. A. (2003). Expression, purification, and efficacy of the type A botulinum neurotoxin catalytic domain fused to two translocation domain variants. Toxicon 41 , 691-701.

Jin, R., Sikorra, S., Stegmann, C. M., Pich, A., Binz, T., and Brunger, A. T. (2007). Structural and biochemical studies of botulinum neurotoxin serotype $\mathrm{C} 1$ light chain protease: implications for dual substrate specificity. Biochemistry 46, 10685-10693.

Keller, J. E., Neale, E. A., Oyler, G., and Adler, M. (1999). Persistence of botulinum neurotoxin action in cultured spinal cord cells. FEBS Lett. 456, 137-142.

Kumaran, D., Rawat, R., Ludivico, M. L., Ahmed, S. A., and Swaminathan, S. (2008a). Structure- and substratebased inhibitor design for Clostridium botulinum neurotoxin serotype A. J. Biol. Chem. 283, 18883-18891.

Kumaran, D., Rawat, R., Ahmed, S. A., and Swaminathan, S (2008b). Substrate binding mode and its implication on drug design for botulinum neurotoxin A. PLoS Pathog. 4, el000165. doi:10.1371/journal.ppat.1000165
Lacy, D. B., Tepp, W., Cohen, A. C., DasGupta, B. R., and Stevens, R. C. (1998). Crystal structure of botulinum neurotoxin type A and implications for toxicity. Nat. Struct. Biol. 5, 898-902.

Li, Y., Dowbenko, D., and Lasky, L. A. (2002). AKT/PKB phosphorylation of p21Cip/WAF1 enhances protein stability of p21Cip/WAF1 and promotes cell survival. J. Biol. Chem. 277, 11352-11361.

Ludivico, M., Smith, L. A., and Ahmed, S. A. (2009). Structure-based design of peptide inhibitors of botulinum neurotoxin serotypes A proteolytic activity. Botulinum J. 1, 297-308.

Montecucco, C., and Schiavo, G. (1995). Structure and function of tetanus and botulinum neurotoxins. Q. Rev. Biophys. 28, 423-472.

Munton, R. P., Tweedie-Cullen, R., Livingstone-Zatchej, M., Weinandy, F., Waidelich, M., Longo, D., Gehrig, P., Potthast, F., Rutishauser, D., Gerrits, B., Panse, C., Schlapbach, R. and Mansuy, I. M. (2007). Qualitative and quantitative analyses of protein phosphorylation in naive and stimulated mouse synaptosomal preparations. Mol. Cell Proteomics 6, 283-293.

Nagy, G., Reim, K., Matti, U., Brose, N., Binz, T., Rettig, J., Neher, E., and Sorensen, J. B. (2004). Regulation of releasable vesicle pool sizes by protein kinase A-dependent phosphorylation of SNAP-25. Neuron 41 417-429.

Nielander, H. B., Onofri, F., Valtorta, F., Schiavo, G., Montecucco, C., Greengard, P., and Benfenati, F. (1995). Phosphorylation of VAMP/synaptobrevin in synaptic vesicles by endogenous protein kinases. J. Neurochem. 65, 1712-1720.

Pang, Y. P., Vummenthala, A., Mishra, R. K., Park, J. G., Wang, S., Davis, J., Millard, C. B., and Schmidt, J. J. (2009). Potent new small-molecule inhibitor of botulinum neurotoxin serotype A endopeptidase developed by synthesis-based computer-aided molecular design. PLoS ONE 4, e7730. doi:10.1371/journal.pone.0007730

Patwardhan, P., and Miller, W. T. (2007). Processive phosphorylation: mechanism and biological importance. Cell. Signal. 19, 2218-2226.

Rawat, R., Ahmed, S. A., and Swaminathan, S. (2008). High level expression of the light chain of botulinum neurotoxin serotype $\mathrm{C} 1$ and an efficient HPLC assay to monitor its proteolytic activity. Protein Expr. Purif. 60, 165-169. 
Rowe, B., Schmidt, J. J., Smith, L. A., and Ahmed, S. A. (2010). Rapid product analysis and increased sensitivity for quantitative determinations of botulinum neurotoxin proteolytic activity. Anal. Biochem. 396, 188-193.

Schiavo, G., Rossetto, O., Catsicas, S., Polverino de Laureto, P., DasGupta, B. R., Benfenati, F., and Montecucco, C. (1993). Identification of the nerve terminal targets of botulinum neurotoxin serotypes A, D, and E. J. Biol. Chem. 268, 23784-23787.

Schiavo, G., Rossetto, O., Santucci, A., DasGupta, B. R., and Montecucco, C. (1992a). Botulinum neurotoxins are zinc proteins. J. Biol. Chem. 267, 23479-23483.

Schiavo, G., Benfenati, F., Poulain, B., Rossetto, O., Polverino de Laureto, P., DasGupta, B. R., and Montecucco, C. (1992b). Tetanus and botulinum-B neurotoxins block neurotransmitter release by proteolytic cleavage of synaptobrevin. Nature 359, 832-835.

Schmidt, J. J., and Stafford, R. G. (2002). A high-affinity competitive inhibitor of type A botulinum neurotoxin protease activity. FEBS Lett. 532, Souayah, N., Karim, H., Kamin, S. S., 423-426. McArdle, J., and Marcus, S. (2006) Severe botulism after focal injection of botulinum toxin. Neurology 67, 1855-1856.

Swaminathan, S., Eswaramoorthy, S., and Kumaran, D. (2004). Structure and enzymatic activity of botulinum neurotoxins. Mov. Disord. 19(Suppl. 8), S17-S22.

Toth, S. I., Smith, L. A., and Ahmed, S. A. (2009). Extreme sensitivity of botulinum neurotoxin domains towards mild agitation. J. Pharm. Sci. 98, 3302-3311.

Walsh, C. T. (2006a). Posttranslational Modification of Proteins, 1st Edn. Englewood, CO: Roberts and Company Publishers.

Walsh, C. T. (2006b). Posttranslational Modification of Proteins: Expanding Nature's Inventory, 1st Edn. Edgewood, CO: Roberts and Company Publishers.

Zuniga, J. E., Schmidt, J. J., Fenn, T., Burnett, J. C., Arac, D., Gussio, R., Stafford, R. G., Badie, S. S., Bavari, S., and Brunger, A. T. (2008). A potent peptidomimetic inhibitor of botulinum neurotoxin serotype A has a very different conformation than SNAP-25 substrate. Structure 16, 1588 1597.

Conflict of Interest Statement: The authors declare that the research was conducted in the absence of any commercial or financial relationships that could be construed as a potential conflict of interest.

Received: 13 February 2012; accepted: 07 May 2012; published online: 04 June 2012.

Citation: Toth S, Brueggmann EE, Oyler GA, Smith LA, Hines HB and Ahmed SA (2012) Tyrosine phosphorylation of botulinum neurotoxin protease domains. Front. Pharmacol. 3:102. doi: 10.3389/fphar.2012.00102

This article was submitted to Frontiers in Experimental Pharmacology and Drug Discovery, a specialty of Frontiers in Pharmacology.

Copyright (C) 2012 Toth, Brueggmann, Oyler, Smith, Hines and Ahmed. This is an open-access article distributed under the terms of the Creative Commons Attribution Non Commercial License, which permits non-commercial use, distribution, and reproduction in other forums, provided the original authors and source are credited. 